\title{
A VIRADA ANTROPOLÓGICA: O RETORNO DO SUJEITO E DA HISTÓRIA
}

\author{
EL GIRO ANTROPOLÓGICO: EL RETORNO DEL SUJETO Y DE LA HISTORIA
}

THE ANTHROPOLOGICAL TURN: THE RETURN OF THE SUBJECT AND HISTORY

\author{
Letícia Negrão CHAMMA ${ }^{1}$
}

RESUMO: A ênfase no campo representacional e a transposição da virada linguística estrutural para a antropologia abriram espaço para novas categorias e novas reflexões na disciplina, que questionam agora não só a possibilidade de uma objetividade total, mas sua própria concepção de representação. Assim, o presente ensaio visa mostrar a influência da virada estruturalista na antropologia a partir de dois núcleos: a) as noções de história e estrutura; b) a presença do autor na etnografia e na produção textual.

PALAVRAS-CHAVE: Virada antropológica. Categorias antropológicas. História. Estrutura. Produção textual etnográfica.

RESUMEN: El énfasis en el campo representacional y la transposición del giro lingüístico estructural hacia la antropología han abierto espacio para nuevas categorías y nuevas reflexiones en la disciplina, que cuestionan ahora no sólo la posibilidad de una objetividad total, sino su propia concepción de representación. Así, el presente ensayo pretende mostrar la influencia del cambio estructuralista en la antropología a partir de dos núcleos: a) las nociones de historia y estructura; b) la presencia del autor en la etnografía y en la producción textual.

PALABRAS CLAVE: Giro antropológico. Categorías antropológicas. Historia. Estructura. Producción textual etnográfica.

ABSTRACT: The emphasis on the representational field and the structural linguistics turn transposition into anthropology have opened space for new categories and new reflections in the discipline, which now question not only the possibility of a complete objectivity, but its own conception of representation. Thus, the present essay aims to show the influence of the structural turn in anthropology from two perspectives: a) the notions of history and structure; b) the presence of the author in ethnography and the textual production.

KEYWORDS: Anthropological turn. Anthropological categories. Story. Structure. Ethnographic textual production.

${ }^{1}$ Universidade Estadual Paulista (UNESP), Araraquara - SP - Brasil. Graduanda em Ciências Sociais. ORCID: <https://orcid.org/0000-0001-9787-5994>. E-mail: leticiachamma@ hotmail.com. 


\section{Introdução}

A problemática que inquietava a antropologia no século $\mathrm{XX}$, sobretudo em sua primeira metade, era a busca de uma linguagem científica e universal para as ciências humanas. A proposta de objetividade na antropologia foi a de superar as barreiras das particularidades e, a partir disso, propor grandes modelos teóricos, capazes de traduzir as culturas. Bronislaw Malinowski (1884-1942), por exemplo, foi fundamental para o estabelecimento da validade científica da observação participante: preocupava-se em demonstrar aos leitores que o que estava em seus livros eram fatos "objetivamente adquiridos, não criações subjetivas" (CLIFFORD, 2008, p. 25). Institui-se, em meados da década de 1920, um novo papel do antropólogo enquanto etnógrafo, o do teórico-pesquisador, ou seja, esses personagens que antes do fim do século XIX eram distintos fundem-se numa nova figura: a do antropólogo profissional, que traduz e descreve os costumes, bem como constrói as teorias gerais sobre a humanidade.

Esse esforço e objetivo da antropologia, isto é, o de se tornar uma disciplina científica, tinha como meios a racionalidade e a objetividade - ideias-valor da episteme ocidental a partir do Iluminismo, segundo Oliveira (2003, p. 92). Dessa forma, é possível observar que as escolas antropológicas da primeira parte do século XX orientavam-se por "paradigmas da ordem" (OLIVEIRA, 2003), dirigindo não só os discursos das diferentes escolas, mas a "gramaticalidade da linguagem antropológica" (OLIVEIRA, 2003, p. 93). Lévi-Strauss (19082009), dentro do que é possível chamar de "Escola Francesa de Sociologia", não escapa dessa lógica. De matriz intelectualista e sincrônica, e no horizonte de um paradigma estruturalista, buscava as formas elementares ordenadoras do pensamento primitivo.

Lévi-Strauss realizou um passo que se tornou um marco na antropologia: transpôs (no sentido de atravessar e transcender) o método da linguística para o tema da cultura. A concepção linguística de Saussure foi fundamental para a virada estruturalista antropológica. Segundo o autor, as línguas são sistemas de representação em que, a partir da construção de modelos estruturais, é possível alcançar as estruturas profundas da linguagem. A língua funciona, pois, como um código entre nossa mente e o mundo, em que não podemos nos perceber fora dessa. A virada linguística estrutural com Saussure traz a ideia de linguagem enquanto um sistema, possível de ser apreendido a partir das relações entre as unidades de linguagem (os fonemas).

O projeto epistemológico do estruturalismo se deu, dessa forma, pelo alargamento da razão humana como simbólica e livre dos sujeitos, isto é, pensamos racionalmente independente de nossa consciência, uma vez que o simbólico é o modo de operação do pensamento humano. 
Isso não exclui o fato de que a razão possui uma objetividade: opera segundo leis e regularidades, constituindo-se, pois, relacionalmente e de acordo com os contextos de interação e com a realidade de comunicação. A ideia é a de que todo pensamento humano opera dando forma aos conteúdos através de uma razão combinatória, através de pares de oposições binárias. O estruturalismo pode ser entendido, então, como um método semiológico de decifração de códigos que, a partir da comparação entre modelos, extrai aquilo que é comum e recorrente em todas as sociedades. Trata-se da busca de universais do espírito humano e o mito, para LéviStrauss, é a matéria universal (não possui autoria) que expressa essa razão simbólica. Uma vez que essa razão se expressa na relação entre natureza e cultura, a regulamentação do incesto se dá como a única regra universal, sendo que seu conteúdo varia culturalmente.

Aqui ainda é possível observar a ideia de que a realidade pode ser observada e apreendida. Para Lévi-Strauss a realidade profunda é relacional, e o objeto real só é encontrado pela totalidade (invisível) das manifestações visíveis, isto é, a realidade empírica imediata não é a realidade. Esta se dá, na verdade, por estruturas inconscientes (que possibilitam o acesso a essa realidade profunda), pelo metacódigo, pelo o que é compartilhado e pela relação dessas unidades entre si. Enfim, para Lévi-Strauss, a estrutura é sempre simbólica, sincrônica e inconsciente e, por conseguinte, toda realidade material e social também é simbólica, carregada de significações. A construção de um metacódigo (sistema dos sistemas) tem como objetivo um modelo que transcenda a aparência dos fenômenos e que seja capaz de apreender a realidade profunda. Assim, a sociedade é feita por representações simbólicas, por níveis de realidade descontínuos, mas que operam sob a mesma lógica (simbólica). Logo, a antropologia moderna, interessada pelos fenômenos simbólicos, assentava sua cientificidade na busca por um denominador comum do pensamento humano nas diversas sociedades. Dessa forma, para LéviStrauss, o conceito de cultura era generalizado, uma manifestação do processo do pensamento simbólico, um universo de dimensões ideativas e valorativas, postas nas dimensões do inconsciente.

Isto posto, vale ressaltar a importância da virada antropológica alimentada por LéviStrauss, uma vez que, bebendo desse espírito de busca por cientificidade, trabalha princípios que se tornaram fundamentais na antropologia, bem como fonte de novas reflexões, possibilitando ou instigando, posteriormente, um movimento pós moderno: uma "segunda virada linguística” (KLINGER, 2007, p. 72) que descontrói a primeira virada linguística estruturalista. 


\section{História e Estrutura: categorias opostas?}

De início, vale resgatar a organização feita por Roberto Cardoso de Oliveira (19282006) das escolas antropológicas, de acordo com o tempo e a tradição. A primeira matriz seria a "Escola Francesa de Sociologia": intelectualista e sincrônica, com o paradigma racionalista e, em sua forma moderna, estruturalista; a segunda, a "Escola Britânica de Antropologia": empirista e sincrônica, com o paradigma estrutural-funcionalista; a terceira, a "Escola Histórico-Cultural”: empirista e diacrônica, com o paradigma culturalista; e, a quarta, a "Antropologia Interpretativista": intelectualista e diacrônica, com o paradigma hermenêutico. Com exceção dessa última, todas essas escolas orientaram-se pelo o que o autor chamou de paradigma da ordem. O ponto levantado é de que é impossível (talvez até insuficiente ou falho) "supor que a subjetividade, o indivíduo e a história sempre estiveram ausentes dos paradigmas da ordem" (OLIVEIRA, 2003, p. 93). O que aconteceu, na verdade, foi um processo de domesticação (e não exclusão) desses elementos, negando sua proeminência.

Lévi-Strauss trabalha esses elementos a partir da relação entre estrutura e história. Em diálogo crítico com os evolucionistas, participa do mesmo debate que Franz Boas (1858-1942) - que vê a necessidade do conhecimento do desenvolvimento histórico para se conhecer uma cultura - e B. Malinowski, que renuncia a história para buscar as motivações universais através da observação de uma dada sociedade -, ambos confrontando a concepção de história conjectural. A ideia de Lévi-Strauss é a de que o método histórico - de caráter monográfico e funcional - assemelha-se ao método etnográfico; aqui, buscava-se a integração dos resultados dos estudos das sociedades chamadas 'complexas' e das sociedades 'primitivas' para conclusões universalmente válidas, ou seja, a partir da observação e análise de grupos humanos em suas particularidades, reconstituir seus modos de vida. O objetivo do etnógrafo-historiador seria de traduzir os processos conscientes e inconscientes em experiências concretas (individuais ou coletivas). O etnógrafo recolheria e apresentaria os fatos observados, organizando esses dados - expressões conscientes da vida social. Já o etnólogo, impotente para atingir o passado histórico, explicaria as descrições e análises formuladas pelos etnógrafos. Semelhante ou baseado no método linguístico, o objetivo do método etnológico seria o de chegar a uma estrutura inconsciente, uma "estrutura subjacente a formulações múltiplas e permanente através de uma sucessão de acontecimentos” (LÉVI-STRAUSS, 1996, p. 37).

Assim, o estruturalismo proposto por Lévi-Strauss tinha como objetivo, tal como o evolucionismo, apreender as leis gerais da sociedade, não mais a partir de leis de evolução cultural (impossíveis de serem estabelecidas), mas através do plano simbólico. Por conseguinte, 
a estrutura seria estudada tanto pelo método histórico quanto pelo método etnográfico, ambos estudando outras sociedades, mas o primeiro no tempo e o segundo no espaço. Aqui, os sistemas de representações são fundamentais para alargar uma experiência particular ao nível de uma experiência geral que se torne acessível para homens de outro lugar e tempo, organizando seus dados em relação às expressões conscientes da vida social; a etnologia organizaria esses dados a partir de suas condições inconscientes e de uma dimensão cultural dos fenômenos coletivos, cujo princípio seria a de uma interpretação válida para outras instituições e costumes. Enfim, para Lévi-Strauss, a história se dá enquanto subjetividade e consciência, sendo necessário atravessá-la para entender não somente sua variação, mas a dimensão estrutural na temporalidade histórica. A potência do método estrutural seria o de trabalhar com esses fragmentos, codificados agora simbolicamente e traduzidos para uma dimensão mais geral que a da experiência particular. Essas manifestações em si não possuiriam substância, sendo apenas variáveis no tempo descritas pela história; para Lévi-Strauss, é a partir das estruturas sincrônicas (recorrentes) que se pode formular as leis gerais dos grupos e achar sua forma estrutural e, portanto, a realidade profunda da cultura e da sociedade.

Fica claro que Lévi-Strauss pretende suspender de sua análise o sujeito e a história, isto é, tudo aquilo que é variação, em busca de uma dimensão inconsciente da cultura e, portanto, de uma lei universal. Marshall Sahlins (1930-), em uma perspectiva crítica à essa, visa recolar o problema da prática e da ação humana enquanto significativa. Para o autor, a história pode ser ordenada culturalmente, a partir da significação das coisas, da mesma forma os esquemas culturais podem ser ordenados historicamente. A ideia é a de que a estrutura deve ser entendida enquanto um objeto histórico, abrindo espaço para a ação criativa dos sujeitos envolvidos, uma vez que as pessoas conferem sentido às coisas baseadas em sua cultura - "a cultura é historicamente reproduzida na ação" (SAHLINS, 2003, p. 7) - ao mesmo tempo em que recriam seus esquemas convencionais - "a cultura é historicamente alterada na ação" (SAHLINS, 2003, p. 7). Dessa forma, a ordem cultural é tanto constituída na sociedade, quanto vivenciada pelas pessoas, sendo seus significados questionados na ação desses sujeitos. Os signos são retomados pela 'consciência simbólica humana', em que as palavras e os nomes das coisas são atualizados cotidianamente, podendo (ou não) se tornar gerais ou consensuais em cada cultura.

De acordo com Sahlins (2003, p. 10), o significado das coisas é contextual e, por isso, desproporcional aos "sentidos dos signos pelos quais são apreendidas". O ponto é que as coisas são mais gerais que os signos, pois, são mais "reais" que suas "distinções e valores"; assim, as coisas e os nomes podem adquirir novas conotações a partir do processo histórico de 'reavaliação funcional das categorias'. Aqui vale resgatar a brilhante formulação de Henrich 
Heine (s/d, s/p): “Outros Tempos! Outros pássaros! Outros pássaros, outras canções!” A ideia fundamental que esse autor traz nos ajuda a expressar o que Sahlins muito bem formulou: mudase o tempo histórico, muda-se a cultura, ou, como o próprio autor disse: "culturas diferentes, historicidades diferentes" (SAHLINS, 2003, p. 11). Em suma, para Sahlins, os significados são postos em movimento na cosmologia, isto é, a estrutura possui uma diacronia interna, uma espécie de "vida cultural das formas elementares" (SAHLINS, 2003, p. 16). Ainda assim, deixa claro que as coisas preservam alguma identidade através da mudança, sustentando uma continuidade da ação cultural:

Aquilo que predomina em toda mudança é a persistência da substância antiga: a desconsideração que se tem pelo passado é apenas relativa. É por esta razão que o princípio da mudança se baseia no princípio da continuidade (SAUSSURE, 1959, p. 74 apud SAHLIN, 2003, p. 190).

Sob essa perspectiva, a sincronia saussuriana tende a "instabilidades lógicas", a uma "ambiguidade permanente" ou a uma "contradição inerente" (SAHLINS, 2003, p. 17). Já na estrutura diacrônica, uma noção de estrutura temporal resolveria essa contradição: “A estrutura, mesmo quando produz estes efeitos contraditórios repetidamente na empiria, não é por si mesma contraditória" (SAHLINS, 2003, p. 17). É por isso que Sahlins parte do exemplo havaiano e da chegada do capitão Cook para abordar a relação entre estrutura e evento, mostrando que a transformação da cultura também é um modo de sua reprodução. Nesse caso, os chefes e os povos havaianos reagiram ao estrangeiro a partir de suas próprias autoconcepções e interesses, recriando as suas próprias distinções de status a partir de sua cultura já constituída. No mundo, na ação, nos atos de referência, as "categorias culturais adquirem novos valores funcionais" (SAHLINS, 2003, p. 174) e, assim, os significados culturais e as relações entre as próprias categorias se alteram, transformando a estrutura.

Sahlins mostra que a visita de Cook, interpretado enquanto um ser divino que irrompera do céu além do horizonte, alterou os sentidos e as relações habituais dos havaianos. Suas reavaliações lógicas se deram, na verdade, como "extensões lógicas dos conceitos tradicionais" (SAHLINS, 2003, p. 176). A transformação estrutural se dá, dessa forma, pela "redefinição pragmática das categorias alterando as relações entre as mesmas" (SAHLINS, 2003, p. 179). Isto posto, Sahlins fundamenta sua crítica às distinções ocidentais que pensam história e estrutura, estabilidade e mudança enquanto categorias opostas: “A história havaiana está, toda ela, baseada na estrutura, na ordenação sistemática de circunstâncias contingentes, ao mesmo tempo que a estrutura havaiana provou ser histórica" (SAHLINS, 2003, p. 180). Para o autor, a cultura funciona como uma espécie de síntese entre estabilidade e mudança, passado e presente, 
diacronia e sincronia, sistema e evento, em que, na reprodução cultural, assimila-se às categorias um novo conteúdo empírico.

Se de acordo com Saussure (apud SAHLINS, 2003, s/p), a objetividade dos objetos é uma consequência do caráter arbitrário do sistema simbólico, para Sahlins, é justamente por essa dupla arbitrariedade do signo em sua referência - segmentação relativa e representação seletiva - que a cultura é um objeto histórico. Fica clara, então, a intrínseca desproporção entre palavras e coisas, em que o signo é reavaliado funcionalmente. A ação cultural é, portanto, para Sahlins, um risco das categorias em referência, em que, na ação, o signo é determinado como um interesse, um valor instrumental para o sujeito ativo.

Assim, o signo posto em ação é submetido às determinações dos processos de consciência e inteligência humana, no qual a cultura organiza a situação atual da ação simbólica, composta duplamente por um passado inescapável - conceitos que organizam e comunicam as experiências que derivam de um esquema cultural preexistente - e um presente irredutível - a singularidade do mundo em ação.

A questão mais verdadeira jaz no diálogo entre sentido e referência, visto que a referência põe o sistema de sentido em situação de risco em relação a outros sistemas: o sujeito inteligente e o mundo intransigente. E a verdade desse diálogo maior consiste da indissolúvel síntese de coisas como passado e presente, sistema e evento, estrutura e história (SAHLINS, 2003, p. 193).

\section{A Presença do Autor e a Autoridade Etnográfica}

A cultura é uma categoria fundamental na antropologia; junto às transformações da própria disciplina enquanto ciência, sua concepção movimentou-se e modificou-se. No processo de alargamento da razão humana enquanto uma razão simbólica, a cultura foi interpretada pelo estruturalismo como um código, em que todo sistema social equivaleria a um sistema de signos que a antropologia seria capaz de apreender nas suas expressões mais longínquas, traduzindo essa linguagem diferente da nossa (ocidental). A ideia é a de que existe um número restrito de variáveis que possibilitam e explicam as combinações possíveis ou realizadas dentre as sociedades existentes. A partir disso, a antropologia teria como objetivo buscar equivalentes situados no inventário geral das sociedades, a fim de encontrar sua estrutura simbólica e construir um modelo capaz de transcender a aparência dos fenômenos. Isso significa que a estrutura não pode ser apreendida através da observação empírica, pois ela é sincrônica e inconsciente; esses sistemas de signos (que funcionam enquanto lentes entre nossa mente e o 
mundo), no entanto, podem ser traduzidos na linguagem do nosso próprio sistema. Dessa maneira, Lévi-Strauss propõe acessar a dimensão invisível (isto é, estrutural) para além dos sujeitos, acessando também o substrato subjacente, o denominador comum que explica as diferenças das e entre as culturas. Para ele a questão da tradutibilidade é essencial, uma vez que é capaz de construir o sistema dos sistemas, possibilitando acessar a realidade profunda do real.

Dentro dessa perspectiva de busca por cientificidade na antropologia, o movimento hermenêutico, ou a também conhecida Antropologia Interpretativista, surge enquanto um movimento crítico à essa concepção. Segundo Klinger (2007, p.72), o reconhecimento do caráter discursivo na antropologia por Geertz corresponde a uma "segunda virada linguística", pós-moderna na antropologia que desconstrói a primeira virada linguística: a estruturalista levistraussiana. O paradigma hermenêutico nega radicalmente o discurso cientificista, bem como reformula os elementos domesticados pelo paradigma da ordem, como a intersubjetividade, a individualidade e a historicidade, que passam a atuar enquanto elementos da desordem (OLIVEIRA, 2003, p. 97).

Isso significa que a Antropologia Interpretativa, implementada pelo paradigma hermenêutico, enquanto crítica sistemática às 'antropologias tradicionais', estaria atualizando, do ponto de vista da matriz disciplinar, a categoria da desordem - aqui sim como verdadeiro impensado da disciplina (OLIVEIRA, 2003, p. 10)

Assim, em meados da década de 1970, o estruturalismo declina enquanto paradigma transdisciplinar, abandonando-se a "possibilidade de formalizar regras universais de formação do sentido, imunes às diferenças observadas na prática" (KLINGER, 2007, p. 73), no entanto, manteve-se a ideia de que "o sociocultural se distingue por seu caráter simbólico de linguagem" (KLINGER, 2007, p. 73). Os anos 70 fora marcado, então, pelo interesse em uma filosofia da linguagem, analítica ou hermenêutica, em que o foco era a "relação entre interlocutores como fonte do sentido da linguagem" (KLINGER, 2007, p. 73). Nesse aspecto, a filosofia de Wittgenstein exerce um papel fundamental no momento em que critica uma concepção ocidental da linguagem, a de "função designativa-instrumentalista-comunicativa" (COSTA; CAMARGO, 2016, p. 102). O que é possibilitado nesse movimento é uma transformação do cerne da reflexão, que deixa de ser a linguagem ideal e torna-se que o indivíduo utiliza a linguagem: "devemos olhar, portanto, os contextos de uso efetivo da linguagem, onde os sujeitos produzem conhecimento, história e cultura" (COSTA; CAMARGO, 2016, p. 103). Enfim, a linguagem, para Wittgenstein, realiza-se nos seus contextos de ação, isto é, nas suas 
"formas de vida" e em seus "jogos de linguagem" - composto pelos elementos linguísticos, pelos sujeitos falantes e pela situação linguística (formas de vida).

Assim, Clifford Geertz (1926-2006), fortemente influenciado por uma teoria do significado, parte de um conceito semiótico de cultura (não mais semiológico), a entendendo como uma teia de significados a serem interpretados, e não códigos a serem decifrados - Geertz marca aqui uma primeira ruptura com o estruturalismo:

Assim, a antropologia hermenêutica de Geertz é pós-estruturalista, pois recoloca o sujeito que tinha sido anulado pelas 'estruturas', mas também não propõe a volta do sujeito ingênuo da hermenêutica clássica (KLINGER, 2007, p. 73).

Para Geertz (1989) não pode existir um núcleo de sentido, esse é, na verdade, produzido no jogo de interpretações, nos quais sujeito e objeto modificam-se simultaneamente. A cultura se dá enquanto sistemas entrelaçados de signos interpretáveis, articulados na ação social e que, somente a partir daí, adquirem significação. Contrário à tradição Iluminista e às demais teorias da cultura, Geertz coloca a impossibilidade de uma comunicação clara, transparente e imediata, uma vez que nosso pensamento é enviesado pela nossa própria tradição cultural. É por isso que o texto antropológico sempre será uma interpretação de segunda ou de terceira via, uma ficção construída e modelada, capaz de descrever densamente uma cultura. A interpretação das culturas se dá, assim, semelhante ao gênero literário do ensaio; tem como tarefa, pois, descobrir as estruturas conceituais que informam os atos dos sujeitos, encontrados no discurso social, bem como construir um sistema do que é genérico ao comportamento humano. A busca por leis gerais é impossível e a análise cultural intrinsecamente incompleta; a antropologia deve, pois, inscrever o significado das formas culturais (presentes em seus usos e na ação social), como um texto a ser interpretado.

Fica claro, então, um passo fundamental que Geertz dá na antropologia: o antropólogo é incapaz de compreender o outro, pois não consegue se situar totalmente na sua comunidade de linguagem. É nesse ponto que Geertz marca uma segunda ruptura com o estruturalismo e abre espaço para um movimento pós-moderno na antropologia: "não existe o outro como tal, mas apenas sua representação" (KLINGER, 2007, p. 74). O que está posto é uma crise do próprio conceito de representação, em que o sujeito não é mais visto como uma entidade prévia do discurso, mas um "efeito da própria atividade interpretativa" (KLINGER, 2007, p. 74). Geertz é fundamental nesse movimento, pois não só questiona a autoridade antropológica baseada na experiência, mas também a própria cientificidade da própria disciplina, fundamentada agora como uma 'descrição densa'. 
Para Geertz, não existe uma observação 'neutra' à maneira de Lévi-Strauss, mas também não existe uma empatia à maneira de Malinowski: a única resposta de Geertz é a confiança no virtuosismo interpretativo do antropólogo (KLINGER, 2007, p. 76).

A antropologia passa, desse modo, por um processo de autocrítica, colocando em questão aspectos de sua própria prática. Uma vez que a possibilidade de retratar uma cultura como um todo já fora negada por Geertz, os limites da capacidade de conhecer o outro passou a ser interrogado, tendo como horizonte o princípio de que a interpretação é sempre parcial. A crítica pós-moderna à Geertz coloca, então, a necessidade de deslocar a interpretação da cultura como um texto para a produção textual em si; o objetivo deixa de ser a cultura observada e passa a ser a representação dessa cultura. A virada pós-moderna, ou pós-estruturalista implica um retorno do autor e o conhecimento da alteridade implica um dilema de representação, que resulta em um:

[...] abandono da expectativa quanto à possibilidade de se captar alguma 'verdade' do outro, e a consideração da linguagem já não como uma matéria inerte e transparente, na qual procura 'conteúdos', e sim como o lugar mesmo onde se produzem as categorias, as identidades, as exclusões e, enfim, os jogos de poder e, portanto, lugar de passagem que entranha conflitos de tradução e representação (KLINGER, 2007, p. 78).

Assim, a antropologia social do século XX coloca em xeque a prática de representação intercultural, uma vez que o "Ocidente não pode mais se apresentar como o único provedor de conhecimento antropológico sobre o outro" (CLIFFORD, 2008, p. 18). Para Clifford (1945), a escrita etnográfica não escapa da representação do outro enquanto um ser abstrato e a-histórico e por isso a etnografia deve ser compreendida junta a um debate político e epistemológico sobre a escrita e a representação do outro. A tradução da experiência para a forma textual baseia-se num processo de múltiplas subjetividades e constrangimentos políticos, em que a autoridade do etnógrafo não foi questionada enquanto provedora da verdade no texto. Dessa forma, a observação participante:

[...] entendida de modo literal (...) é uma fórmula paradoxal e enganosa, mas pode ser considerada seriamente se reformulada em termos hermenêuticos, como uma dialética entre experiência e interpretação (CLIFFORD, 2008, p. $32)$.

A antropologia clássica, então, distinguiu interpretação e interlocução, fazendo a tradução textual da experiência substancialmente diferente da experiência em si: “(...) estes textos se tornaram evidências de um contexto englobantes, uma 'realidade cultural"" (CLIFFORD, 2008). 
[...] a antropologia interpretativa, ao ver as culturas como conjuntos de textos (...) e ao ressaltar a inventiva poética em funcionamento em toda representação coletiva, contribuiu significativamente para o estranhamento da autoridade etnográfica (CLIFFORD, 2008, p. 39).

Para James Clifford, Geertz não escapa aos limites gerais da antropologia tradicional, ou seja, retrata a realidade de outras culturas sem colocar a sua própria em questão. A experiência e atividade interpretativa do etnógrafo, no entanto, não podem ser consideradas inocentes, ela deve se dar enquanto uma negociação construtiva, expressando não somente o monólogo do autor-pesquisador, mas das diversas subjetividades e nuances contextuais que atravessam o jogo político da experiência etnográfica. Da mesma forma que Lévi-Strauss e Geertz são fortemente influenciados pelas filosofias linguísticas de suas respectivas épocas, Clifford bebe da concepção linguística de Bakhtin, resgatando o caráter intencional que perpassa a linguagem bem como insere uma concepção heteróglota do mundo e, ou talvez, da comunidade de linguagem. O que Clifford visa ressaltar é a impossibilidade de uma "posição neutra no campo de poder dos posicionamentos discursivos" (CLIFFORD, 2008, p. 42), sem, no entanto, eliminar a autoridade monológica - o que somente reprimiria o "fato inescapável da textualização" (CLIFFORD, 2008, p. 44).

A ideia é deslocar o antropólogo e construí-lo enquanto um personagem distinto na narrativa, entendendo a cultura como um diálogo aberto, plural e fora do controle de qualquer indivíduo que tente apresentá-la enquanto o real. O discurso etnográfico deve ser invadido pela concepção de polifonia e de heteroglossia, possibilitando uma estratégia textual alternativa. Os chamados informantes devem ser representados como indivíduos que são: específicos, com nomes próprios reais e cheios de intenções. O que Clifford propõe, então, não é um modelo de diálogo, mas uma partilha da autoria baseada na polifonia, ou seja, sugere um trabalho que seja aberto para "leituras não especificamente intencionais" (CLIFFORD, 2008, p. 54). Enfim, o que não pode ser desconsiderado ou ignorado são os pressupostos políticos e epistemológicos embutidos na escrita etnográfica.

O debate sobre a presença do antropólogo profissional é essencial, pois foi a sua presença no texto e na exposição dos dados que serviu como validade científica da antropologia, baseada na experiencia pessoal para a produção do conhecimento. Essa presença, no entanto, carrega uma ambiguidade em si mesma: a da experiência pessoal que deve ser objetiva e científica. A legitimação da figura do antropólogo profissional se deu, então, junto com a legitimação da observação participante, uma vez que só é possível compreender uma cultura através da imersão em seu cotidiano. O antropólogo deveria, desse modo, reelaborar sua experiência etnográfica pessoal para "transformá-la em uma descrição objetiva (científica) de 
uma cultura como um todo" (CALDEIRA, 1988, p. 137). Não só, esse novo gênero literário foi legitimado por convenções textuais: estruturação a partir das instituições (ou unidades) que se acreditava determinarem uma sociedade; ausência do autor no texto como garantia de cientificidade; exposição da experiência pessoal em segundo plano; falar do povo em geral, não de indivíduos específicos; ênfase no caráter de realidade (acúmulo de detalhes da vida cotidiana); apresentar o ponto de vista nativo representado pelo antropólogo que 'esteve lá'; generalizar; cientificidade; e competência linguística.

A crítica feita a esse modelo se deve essencialmente à presença excessiva do autor no texto que, apesar de ocultada, era a única existente. Para Teresa Caldeira (1988), se a presença do autor no texto demonstra um excesso, na mediada em que o antropólogo constrói a cultura enquanto uma totalidade que pode ser apreendida, isso também significou uma ausência: a do questionamento da presença e da inserção do antropólogo no campo e no texto. A presença excessiva do autor é, na verdade, insuficientemente crítica sobre o seu papel na produção de representações e de conhecimento, uma vez que está imersa em relações de desigualdade e poder no processo comunicativo, bem como na própria definição dos enunciados que podem ser aceitos como verdadeiros. É nesse sentido que as alternativas pós-modernas tentam reinventar os textos e a crítica cultural; todavia, restringiu-se, em sua maioria, às formulações textuais.

Geertz e sua antropologia hermenêutica foram fundamentais para a possibilidade teórica de uma crítica pós-moderna. Para esses, porém, seu rompimento foi apenas parcial - com o processo de produção da interpretação -, pois não considerou a separação entre observador e observado. A etnografia deve ser uma negociação, um diálogo, uma troca entre multiplicidades de vozes, e não uma interpretação sobre essas. A ideia é diluir o autor no texto e minimizar sua presença, de forma a abrir espaço para vozes e perspectivas que antes só apareciam pelo espectro do autor. O etnógrafo agora retrata sua experiência vivida, sem reelaborá-la na produção textual, inscrevendo os processos comunicativos de diversos sujeitos individuais, inclusive o próprio autor.

Os antropólogos pós-modernos, contudo, dão valor de objetividade à diversidade, pressupõe sua irredutibilidade e negam a possibilidade de reconstruir uma totalidade que dê sentido a todas as posições diversas. A diversidade irredutível de experiências é, então, o dado com que o antropólogo pós-moderno tem que trabalhar e achar meios de representar (CALDEIRA, 1988, p. 142).

Com a mudança da concepção do papel e da posição do etnógrafo, muda-se também a noção de leitor; esse passa a ser "participante ativo na construção do sentido do texto" 
(CALDEIRA, 1988, p. 143), que agora só sugere conexões de sentido. Para Caldeira (1954-), o movimento pós-moderno esqueceu uma de suas próprias raízes: a dimensão política e a crítica cultural. Enfim, a discussão textual não se sustenta por si só e, ao mesmo tempo que pode abrir espaço para novas possibilidades, não necessariamente garantem um novo enquadramento do autor e de seu conhecimento (RABINOW, 1985, p. 8 apud CALDEIRA, 1988, p. 143). A discussão deve, na verdade, estar aliada a uma análise que questione e considere as relações de poder existentes.

O pós-modernismo na antropologia tem se caracterizado mais por um trabalho de desconstrução de textos etnográficos clássicos e de proposição de alternativas textuais do que pela produção de etnografias que levem em conta as novas regras, não só em relação ao texto, mas também à crítica cultural (CALDEIRA, 1988, p. 145).

A questão agora é que a possibilidade de representação de uma cultura sempre será em seus aspectos parciais. Assim, para Caldeira (1988, s/p), se a Antropologia Clássica fora marcada por uma presença excessiva do analista e uma ausência do questionamento do papel do autor, bem como de seu estatuto de representador, a Antropologia Pós-Moderna foi circunscrita por uma presença insuficiente do analista e de relatividade da voz do autor que não analisou nada. Para Caldeira (1988, s/p), então, a autoridade monológica do antropólogo não pode mais ser ignorada enquanto uma grande problemática, ainda assim, não se pode perder de vista o papel do antropólogo na prática etnográfica e na produção textual, enquanto um produtor de um contradiscurso e um crítico, inclusive de sua própria sociedade. Enfim, Caldeira afirma que antropologia deve se enquadrar numa perspectiva mais política:

O estilo do texto se define em função do objeto e do tipo de análise que se pretende - e talvez seja da consciência dessa flexibilidade mais do que de receitas textuais que nós precisemos. Segundo eu o vejo, faz parte do novo papel do antropólogo/autor a busca do estilo que melhor se adapte aos seus objetivos, a definição crítica desses objetivos, e a responsabilidade pelas suas escolhas (CALDEIRA, 1988, p. 157).

\section{Considerações finais}

A passagem do século XX para o século XXI foi marcada por grandes rupturas epistemológicas que orientaram a construção da antropologia. Segundo Klinger (2007), existem duas críticas que são fundamentais nesse processo: à concepção de um sujeito transparente a si mesmo e à noção de representação da episteme moderna. Se para Rabinow (1986, p. 243 apud KLINGER, 2007, p. 48) "conhecer é representar adequadamente o que está fora da mente", 
Derrida acaba por questionar o próprio conceito de representação e, junto a esse, os de tradução e de linguagem. Assim, o próprio indivíduo, determinado como sujeito se interpreta na estrutura da representação:

Quando o homem determina tudo o que existe como representável, ele mesmo se põe em cena, no círculo do representável, colocando-se a si mesmo como a cena da representação (KLINGER, 2007, p. 49).

Dessa forma, o sujeito retorna na prática de escritura em primeira pessoa: “o autor hoje fala com sua própria voz, mas avisa ao leitor que não deve confiar em sua versão da verdade" (LASCH, 1983, p. 42 apud KLINGER, 2007, p. 50). Segundo a autora, o discurso sobre o outro acaba por dobrar-se sobre si mesmo, transformando-se em uma tautologia, em que a tradução “se mostra como o lugar de linguagem impossível" (KLINGER, 2007, p. 64). É por isso que nos anos 1980, a antropologia se concentra no questionamento sobre sua própria autoridade em produzir representações válidas sobre o outro. O legado pós-moderno eleva o outro à posição de sujeito político (e não mais objeto passível do conhecimento), que "negocia seu lugar na arena da representação" (KLINGER, 2007, p. 169), uma vez que a linguagem - dentro de um conflito de tradução ou não-tradução - também se mostra como um lugar político.

Isto posto, vale ressaltar o papel fundamental das teorias da linguagem nesse processo. Assim como a virada estrutural linguística foi fundamental para Lévi-Strauss, Wittgenstein ao dirigir o cerne da reflexão parar a situação de interação que o homem utiliza a linguagem, possibilitou uma transformação substancial na forma de se fazer etnografia. O papel do antropólogo deixa de ser o de buscar uma lei universal dentro de uma realidade profunda que pode ser observada, apreendida e descrita. O etnógrafo deve, para Geertz (1989) - que fomenta uma segunda virada -, através de um esforço intelectual, descrever densamente o manuscrito estranho com falas que são, na verdade, tendenciosas, interpretando assim a cultura que é pública; não pode mais, no entanto, situar-se plenamente em uma outra comunidade de linguagem sem levar para o campo as suas próprias referências.

Dessa forma, a virada estruturalista é fundamental para as transformações dadas na antropologia. A partir do momento que enfatiza o campo representacional, possibilita uma perspectiva pós-estruturalista da antropologia e, portanto, crítica dessa mesma abordagem. A questão fundamental para os principais autores abordados é a realidade humana e a ação humana como significativas. Sahlins resgata a importância do sujeito como essencial para os esquemas simbólicos e culturais, em que a estrutura se abre à história e o entendimento da ação social deve considerar as transformações de seus códigos pelos sujeitos e pela reflexão humana sobre a própria cultura. Enquanto isso, Geertz recusa uma abordagem semiológica - 
fundamental para o estruturalismo antropológico -, uma vez que não basta decifrar os códigos de uma cultura (pois a linguagem não é transparente), mas sim compreender sua ação significativa, isto é, sua dimensão valorativa.

A palavra e a significação deixam de possuir um significado imanente e, para fazer sentido, devem estar dentro de um contexto de interação, isto é, dentro de uma comunidade de linguagem; esse define o significado das ações e das palavras. Em suma, o signo, definido pelo tipo de relação entre o representante e o representado, deixa de ser entendido como fixo e passa a ser provisório. A partir disso, entende-se que assim como o mundo, a cultura é constituída e constituinte das relações humanas, abrindo-se a possibilidade de redefinição do mundo e a da existência de um agente ativo, que apropria e ressignifica o mundo: o que as coisas representam depende das interações. Desse modo, a crise da representação na antropologia questiona o próprio saber científico enquanto uma forma de discurso que não pode mais restringir-se a um único autor soberano. A intersubjetividade, a individualidade e a historicidade retornam agora como horizontes que circunscrevem a antropologia contemporânea, que:

Finalmente tornou a questão epistemológica um problema de consideração inevitável para qualquer investigação etnográfica que se pretenda contemporânea e consistente com a atualidade (modernidade ou pósmodernidade, não importa) da Antropologia (OLIVEIRA, 2003, p. 103).

O retorno desses elementos à nova antropologia faz com que a carga da autoria, segundo o próprio Geertz, seja muito mais pesada do que já foi. Esse processo, no entanto, não pode se restringir à produção textual, mas deve ser levado também para a própria prática etnográfica: fazer antropologia hoje significa posicionar-se politicamente. Não é mais possível ignorar as problemáticas levantas tanto por Sahlins, quanto por Geertz, seus críticos, como Clifford e por Teresa Caldeira. A antropologia imersa em uma determinada comunidade de linguagem também é circunscrita por relações de poder, na prática etnográfica e na produção textual. Enfim, os elementos que impulsionam a disciplina não podem deixar de ser questionados, mas também não podemos perder de vista a formulação de uma crítica cultural, sobretudo, de nós mesmos.

AGRADECIMENTOS: agradeço meu companheiro Gabriel Augusto Vilela pela edição e apoio para a realização desse artigo. Agradeço também minha professora Ana Lúcia de Castro, sem a qual não seria possível essa publicação. 


\section{REFERÊNCIAS}

CALDEIRA, Teresa Pires do Rio. A Presença do Autor e a Pós-Modernidade em Antropologia. Novos Estudos CEBRAP, nº 21, julho de 1988, pp. 133-157.

CLIFFORD, James. A Experiência Etnográfica: Antropologia e Literatura no séc. XX. (Org.) José Reginaldo Santos Gonçalves. 3ª ed. Rio de Janeiro: Editora UFRJ, 2008.

COSTA, Leandro Sousa; CAMARGO, Leonardo Nunes. Notas sobre Filosofia, Linguagem e Antropologia em Investigações Filosófica de Ludwig Wittgenstein. Diaphonía, v.2, n. II: 2016.

GEERTZ, Clifford. Uma Descrição Densa: por uma teoria interpretativa da cultura. In: A Interpretação das Culturas. Rio de Janeiro: Ed. Guanabara Koogan, 1989.

KLINGER, Diana Irene. Escritas de si, escritas do outro: o retorno do autor e a virada etnográfica. Rio de Janeiro: 7Letras, 2007.

OLIVEIRA, Roberto Cardoso de. Sobre o Pensamento Antropológico. $3^{\text {a }}$ ed. Rio de Janeiro: Tempo Brasileiro, 2003.

LÉVI-STRAUSS, Claude. Introdução: História e Etnologia. In: Antropologia Estrutural. Rio de Janeiro: Tempo Brasileiro, 1996.

SAHLINS, Marshall. Ilhas de História. Rio de Janeiro: Jorge Zahar Ed., 2003.

\section{Como referenciar este artigo}

CHAMMA, Letícia Negrão. A Virada Antropológica: o retorno do sujeito e da história. Rev. Sem Aspas, Araraquara, v.7, n.2, p. 233-248, jul./dez., 2018. E-ISSN: 2358-4238. DOI: 10.29373/sas.v7i2.12493

Submetido em: 20/12/2018

Aprovado em: 10/01/2019 